\title{
Mapping Global Risk of River Flood Mortality
}

\author{
Junlin Zhang, Xinli Liao, and Wei Xu
}

\section{Background}

Globally, river flooding induced by heavy rainfall frequently causes fatalities every year (Jongman et al. 2015; CRED and UNISDR 2018; CRED 2019). Particularly, heavy rainfall will increase in the future with climate warming (Liao et al. 2019). This could lead to greater rain-induced local flooding in some watersheds or regions (IPCC 2012). Besides, exposed populations to floods are increasing with the socioeconomic development (Jongman et al. 2015; Winsemius et al. 2018; Liao et al. 2019).

Generally, river flooding risk assessment has two steps. The first is to simulate river flooding hazard using hydrological or hydrodynamic model and inundation model, and the second is to calculate affected populations by overlaying the population data and flood hazard maps, and the results are used to assess the risk of affected population by floods (Arnell and Gosling 2016; Lim et al. 2018). Projected future precipitation and social-economic datasets provide a basis for these studies. However, when assessing risks in the population, most studies are concerned with the affected population (Alfieri et al. 2015; Dottori et al. 2016; Wing et al. 2018) and few studies concern mortality risks. Shi and Kasperson (2015) and Jongman et al. (2015) assessed the mortality risk using baseline mortality rate. Kinoshita et al. (2018) simulated changing mortality vulnerability with time

Authors: Junlin Zhang, Xinli Liao, Wei Xu.Map Designers: Junlin Zhang, Jing'ai Wang, Ying Wang.Language Editor: Wei Xu.

J. Zhang $\cdot$ X. Liao $\cdot$ W. Xu ( $₫)$

Faculty of Geographical Science, Beijing Normal University,

Beijing, 100875, China

e-mail: xuwei@bnu.edu.cn

W. Xu

State Key Laboratory of Earth Surface Processes and Resource

Ecology, Beijing Normal University, Beijing, 100875, China to assess risks, but the vulnerability is measured by an index rather than vulnerability functions that involve certain physical processes. The difficulty of mortality risk research is lacking proven vulnerability functions. In addition, many studies focus on the risk at the country and regional levels, lacking grid level high spatial resolution results.

In order to address the issues, this study assessed the global mortality risks from floods by two main steps. The first was to develop mortality vulnerability functions for all countries by revising an existing vulnerability function. Then future potential death tolls of the 2030s and the 2050s were estimated at the $2.5^{\prime}$ grid level under the Representative Concentration Pathway (RCP) and Shared Socioeconomic Pathway (SSP) scenarios of RCP4.5-SSP2 and RCP8.5-SSP3. The results were compiled to produce the risk maps at the $0.25^{\circ}$ grid level and country level.

\section{Method}

Figure 1 shows the technical flowchart for mapping flood mortality risk of the world. The study revised the existing vulnerability functions by adjustment coefficient that is calculated based on recorded death tolls. Then future death tolls were estimated using predicted inundation data and population data, and the adjusted vulnerability functions. Future death tolls at the grid level were then aggregated to other geographic units. Finally, the risk size and model uncertainty are analyzed.

\subsection{Estimation of Risks}

\subsubsection{Estimation of Losses for the Baseline Period}

The mortality vulnerability function is represented by Eq. (1) (Jonkman et al. 2008). Using the function, historical death tolls were estimated by Eqs. (2) and (3). 


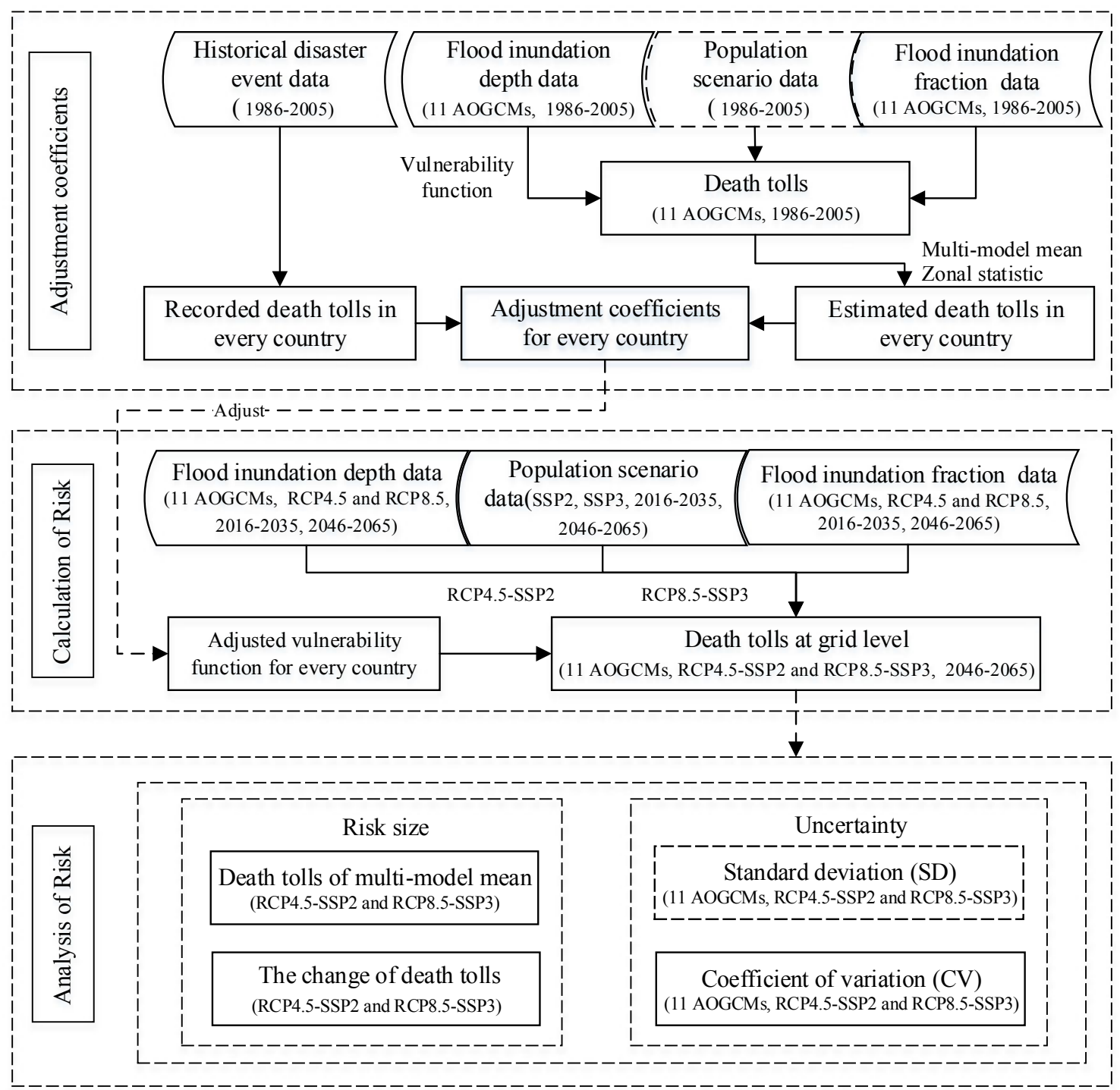

Fig.1 Technical flowchart for mapping global risk of river flood mortality. AOGCM = Atmosphere-Ocean General Circulation Model; $\mathrm{RCP}=$ Representative Concentration Pathway; SSP = Shared Socioeconomic Pathway

$$
V(d)=\Phi\left[\frac{\ln (d)-7.60}{2.75}\right]
$$

where $\Phi$ is the cumulative normal distribution. $d$ is the water depth.

$$
\begin{aligned}
L_{h i s_{-}{ }_{\perp} j} & =V\left(d_{h i s \_i \_j}\right) \times S_{h i s \_j} \times f_{h i s \_i \_j} \\
L_{h i s} & =\frac{1}{11 \times 20} \sum_{j=1}^{20} \sum_{i=1}^{11} L_{h i s \_i \_j}
\end{aligned}
$$

where $i$ is the order of the 11 Atmosphere-Ocean General Circulation Models (AOGCMs); $j$ is the sequence of the 20 years; $h i s$ is the baseline period (1986-2005); $L_{h i s_{-} i_{-} j}$, $d_{\text {his } i j j}$, and $f_{\text {his } i_{j} j}$ are the estimated death tolls, water depth, and inundation fraction for the $i$ th AOGCM in the $j$ th year for the baseline period, respectively; $S_{h i s_{-} j}$ is the population size in the $j$ th year of the baseline period; $L_{h i s}$ is the annual average death tolls, that is, the multi-model ensemble for the baseline period; $V(d)$ is the vulnerability function.

\subsubsection{Calculation of Adjustment Coefficients}

The study revised the mortality vulnerability function (Eq. 1) for countries to reduce the diversity of vulnerability functions in different areas. 
Using Eq. (4), the adjustment coefficients ( $K_{c}$ values) were calculated for the countries with total recorded deaths and estimated deaths both greater than zero during the baseline period. On this basis, the adjustment coefficient is the minimum of above calculated $K_{c}$ values for the countries with total recorded death tolls equal to zero during the baseline period; and the adjustment coefficient is the average of above calculated $K_{c}$ values for the countries with total recorded death tolls greater than zero but total estimated deaths equal to zero.

$$
K_{c}=\frac{\sum_{j=1}^{20} S L_{h i s \_c \_j}}{L_{h i s \_c}}
$$

where $K_{c}$ is the adjustment coefficient of country $c ; j$ represents the sequential number of the 20 years in the baseline period; $S L_{h i s_{-} c_{j} j}$ is the recorded death tolls of country $c$.

The adjusted vulnerability function is shown in Eq. (5).

$$
\operatorname{Adj}_{c}(d)=K_{c} \times V(d)
$$

where $\operatorname{Adj} V_{c}(d)$ is the adjusted vulnerability function of country $c$.

\subsubsection{Calculation of Future Losses and Change}

Future death tolls of a grid in country $c$ were estimated according to Eq. (6), based on future predicted inundation and population data and adjusted vulnerability function. Next, the study averaged the results of 20 years for all AOGCMs (Eq. 7) to compute uncertainties; then we averaged the results of the 11 AOGCMs as the death tolls of the 2030 s or the 2050s to reduce model uncertainties (Eq. 8). Finally, the changes of death tolls from the baseline period to future periods were calculated by Eq. (9).

$$
L_{\text {fut } \_i \_j}=A d j V_{c}\left(d_{f u t \_i \_j}\right) \times S_{f u t \_j} \times f_{\text {fut } \_i \_j}
$$

where $L_{f u t \_i \_j}, d_{f u t \_i \_j}$, and $f_{\text {fut } i_{-} j}$ are the estimated death tolls, water depth, and inundation fraction for the $i$ th AOGCM in the $j$ th year for a future period, respectively; $S_{f u t \_j}$ is the population data in the $j$ th year of a future period.

$$
L_{f u t \_i}=\frac{1}{20} \sum_{j=1}^{20} L_{f u t \_i \_j}
$$

where $L_{\text {fut } i}$ is the average death tolls of 20 years (20162035 or 2046-2065) for the $i$ th AOGCM.

$$
L_{f u t}=\frac{1}{11} \sum_{i=1}^{11} L_{f u t \_i}
$$

where $L_{f u t}$ is the death tolls of the 2030s or the 2050s for the multi-model ensemble, which averaged the results from the 11 AOGCMs.

$$
\Delta L=L_{f u t}-L_{h i s}
$$

where $\Delta L$ is the change of death tolls for the 2030s or the 2050 s relative to the baseline period.

\subsection{Model Uncertainty}

The result uncertainty of multi-models is measured by standard deviation (Eq. 10) and coefficient of variation CV, the ratio of $S D$ to $L$ in Eq. 10 .

$$
S D=\sqrt{\frac{\sum_{i=1}^{11}\left(L_{i}-L\right)^{2}}{11}}
$$

where $L_{i}$ is the average death tolls of 20 years for the $i$ th AOGCM $\left(L_{\text {his_i } i}\right.$ or $\left.L_{f u t_{-} i}\right) . L$ is the average death tolls of 20 years for the multi-model ensemble $\left(L_{h i s}\right.$ or $\left.L_{f u t}\right)$.

\section{Results}

Globally, the annual average death tolls of the 2030s are approximately 21 thousand persons for the RCP4.5-SSP2 scenario and 23 thousand persons for the RCP8.5-SSP3 scenario; they increase 0.57 and 0.69 times relative to the baseline period, respectively. The annual average death tolls of the 2050s are approximately 26 thousand persons for the RCP4.5-SSP2 scenario and 32 thousand persons for the RCP8.5-SSP3 scenario; they increase 0.88 and 1.31 times relative to the baseline period. The patterns of spatial distribution are similar for different scenarios; high-risk areas are located in East Asia, South Asia, and Southeast Asia, particularly in eastern coastal China and the Ganges River Basin. 


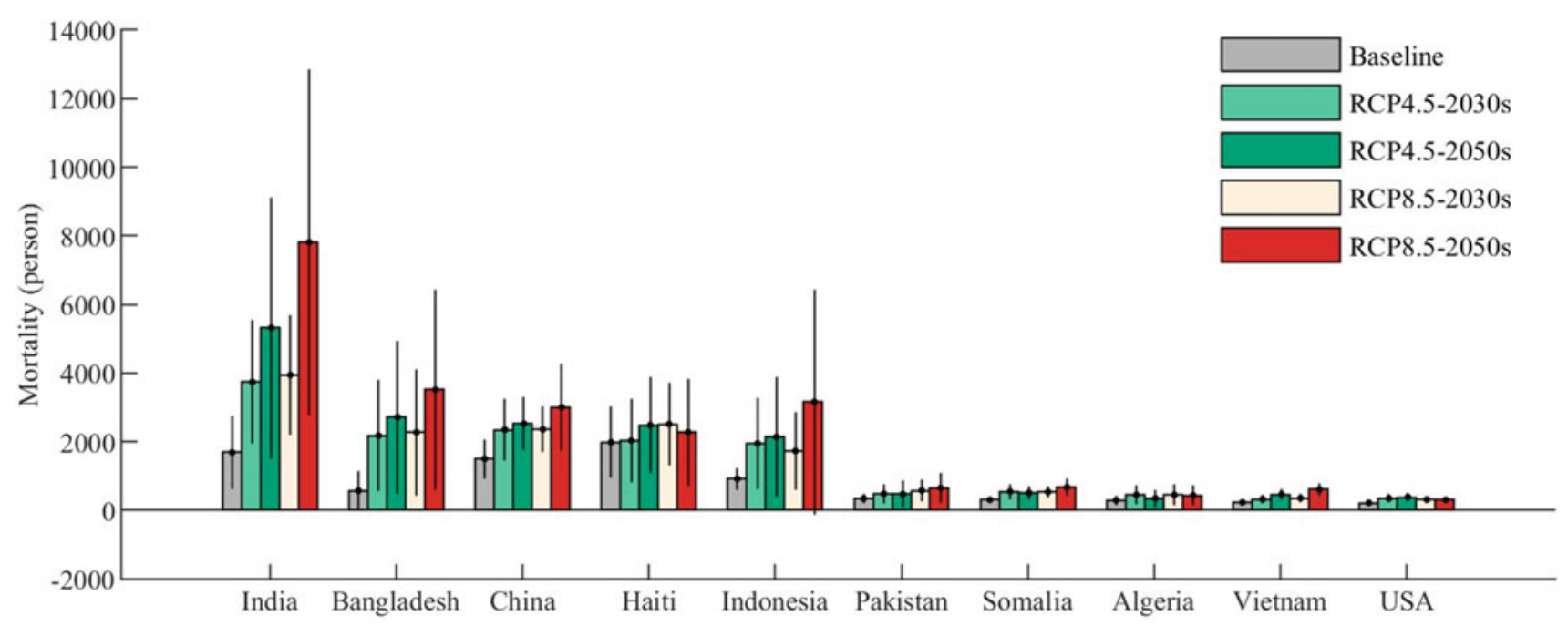

Fig.2 Annual average death tolls of the top 10 high-risk countries (in descending order by death toll). The error bar represents the standard deviations across the 11 Atmosphere-Ocean General Circulation Models (AOGCMs)

Using zonal statistics of the death toll results, we calculated the annual average death tolls at the national level. Figure 2 shows the annual average death tolls and errors (measured by standard deviation) of the top ten high-risk countries. The death tolls are higher for India, Bangladesh, China, Haiti, and Indonesia, and lower in Pakistan, Somalia, Algeria, Viet Nam, and the United States. For most countries, the death tolls of the 2050s are higher than that of the 2030s; and the death tolls of the RCP8.5-SSP3 scenario are higher than that of the RCP4.5-SSP2 scenario. The changes of death tolls are higher in India and Bangladesh, increasing 1.22-3.63 times for India and 2.82-5.16 times for Bangladesh. The risk changes of Haiti are the lowest, about 0.03-0.27 times (Fig. 2). 


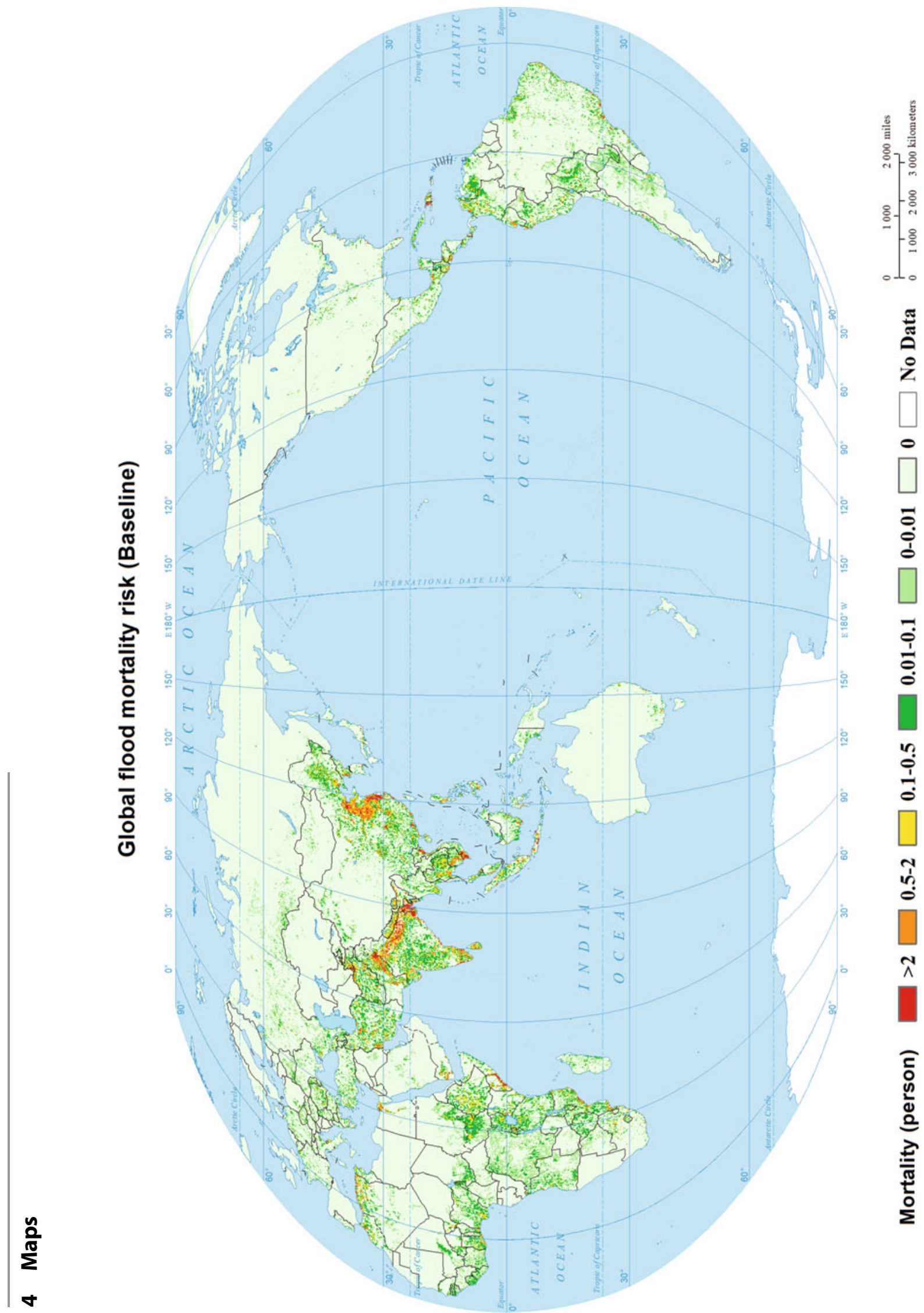




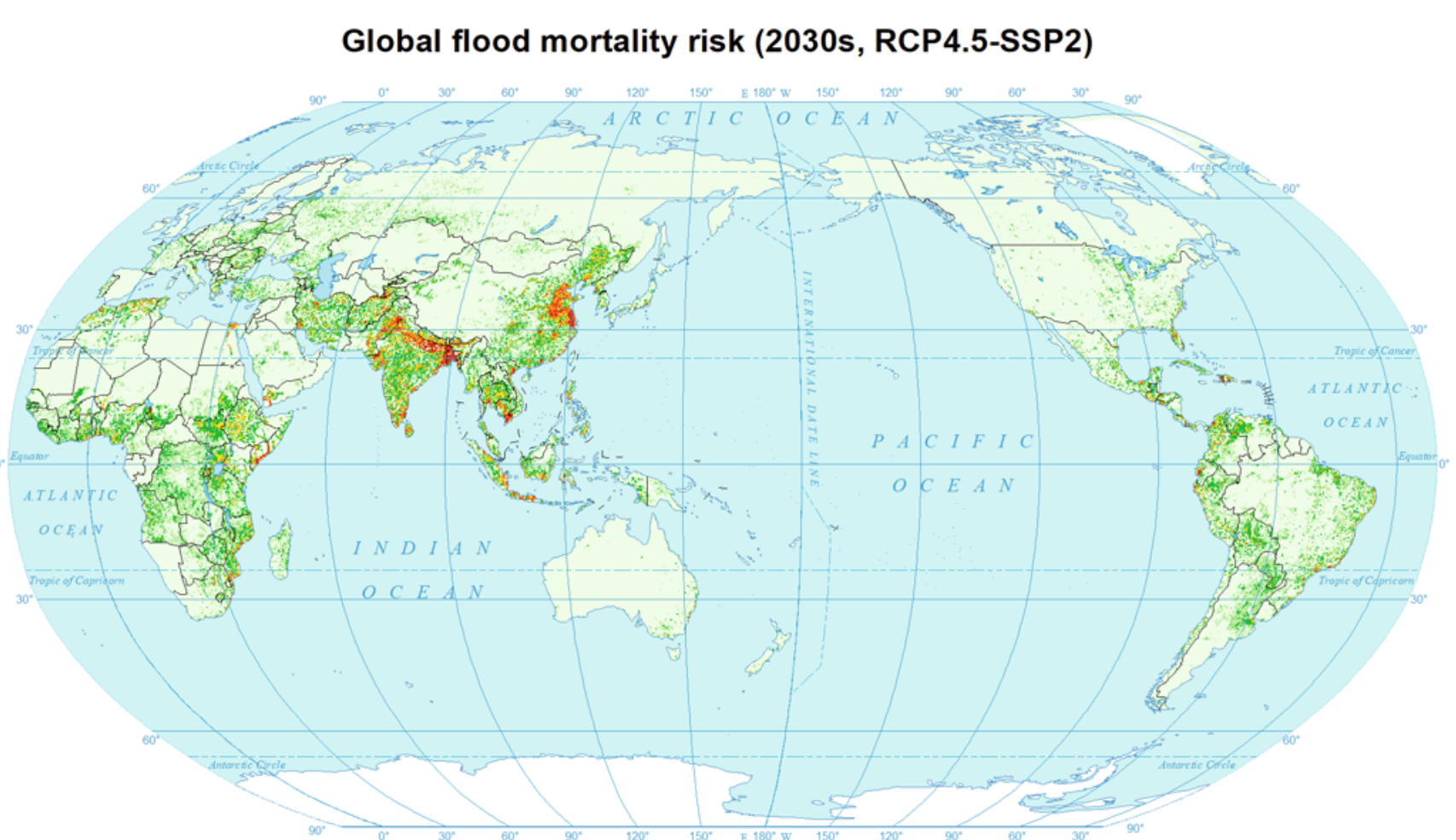

Mortality (person) $\square>2 \square$ 0.5-2 $\square$ 0.1-0.5 $\square$ 0.01-0.1 $\square$ 0-0.01 $\square$ 0 $\square$ No Data $\begin{aligned} & 0 \\ & \stackrel{1}{1} 1000 \quad 2000 \text { miles } \\ & 1000\end{aligned}$

Global flood mortality risk (2030s, RCP8.5-SSP3)

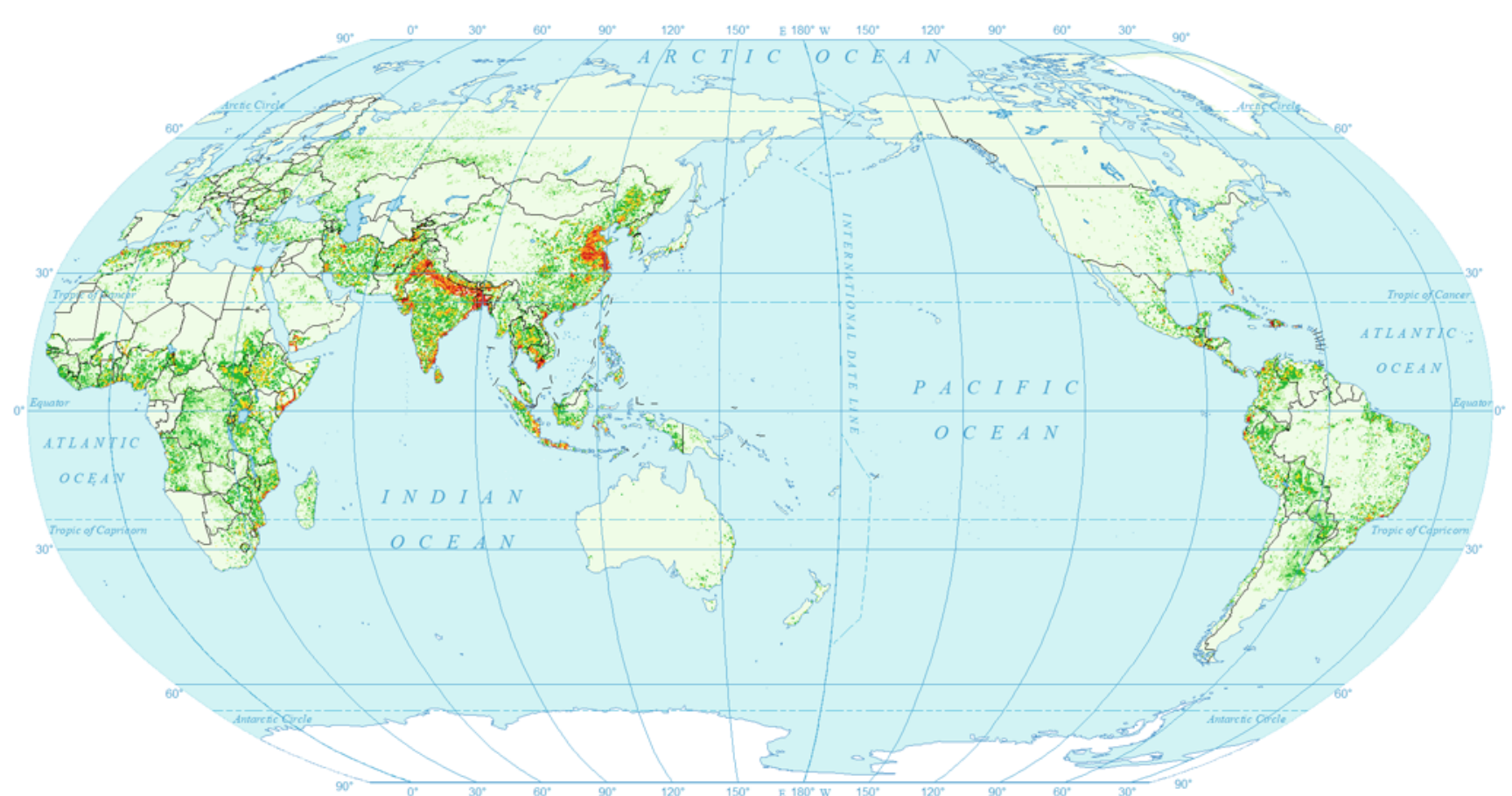

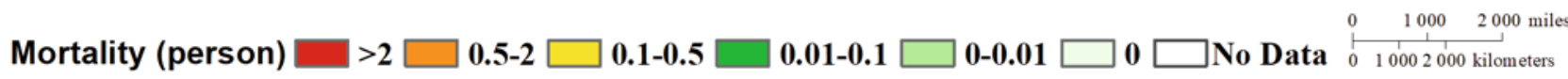


Global flood mortality risk (2050s, RCP4.5-SSP2)

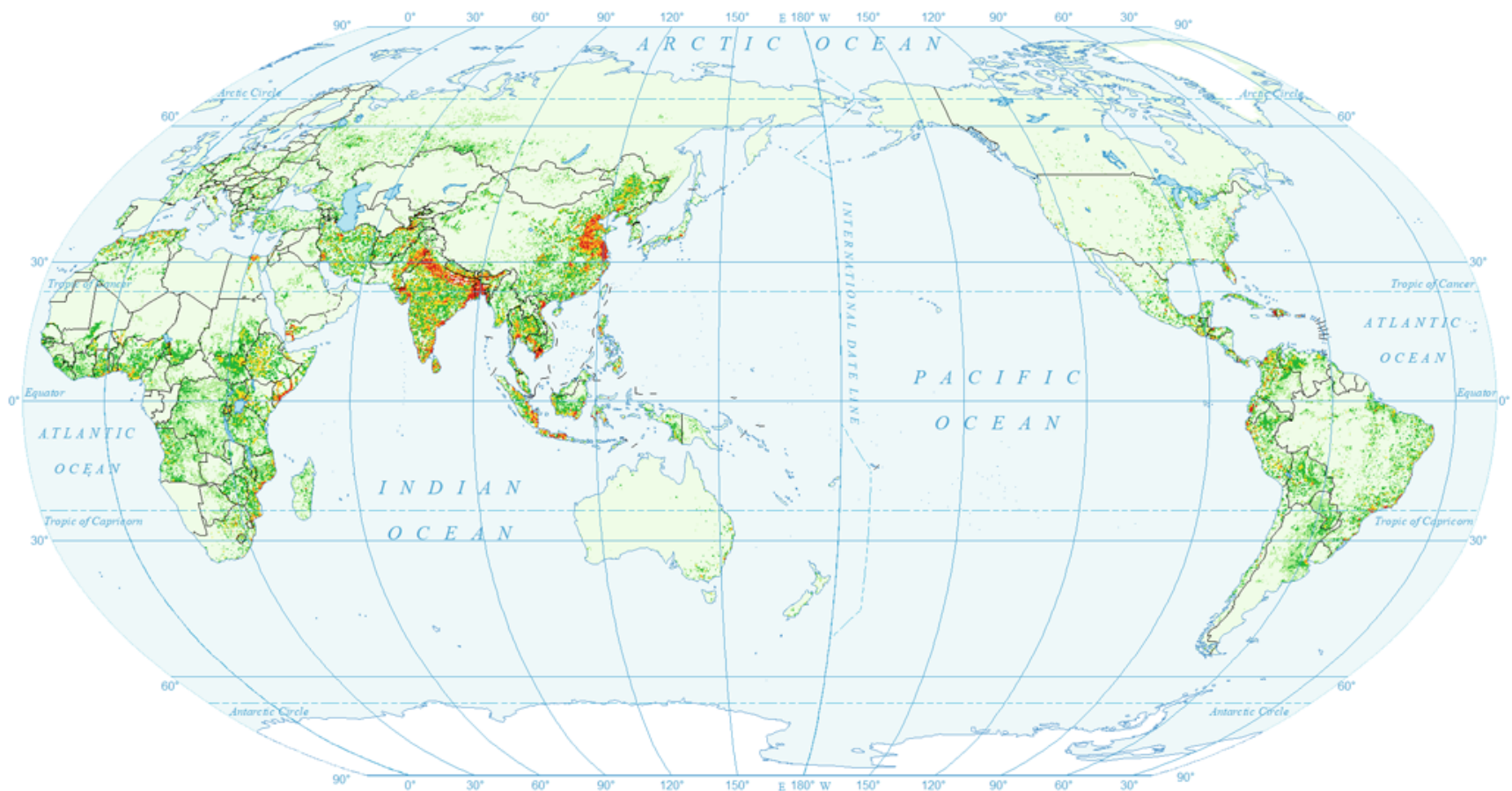

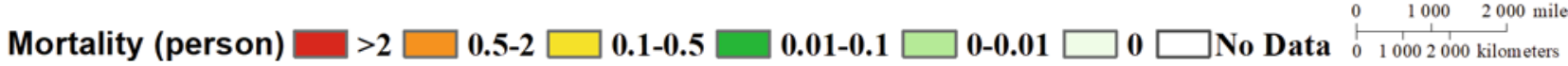

\section{Global flood mortality risk (2050s, RCP8.5-SSP3)}

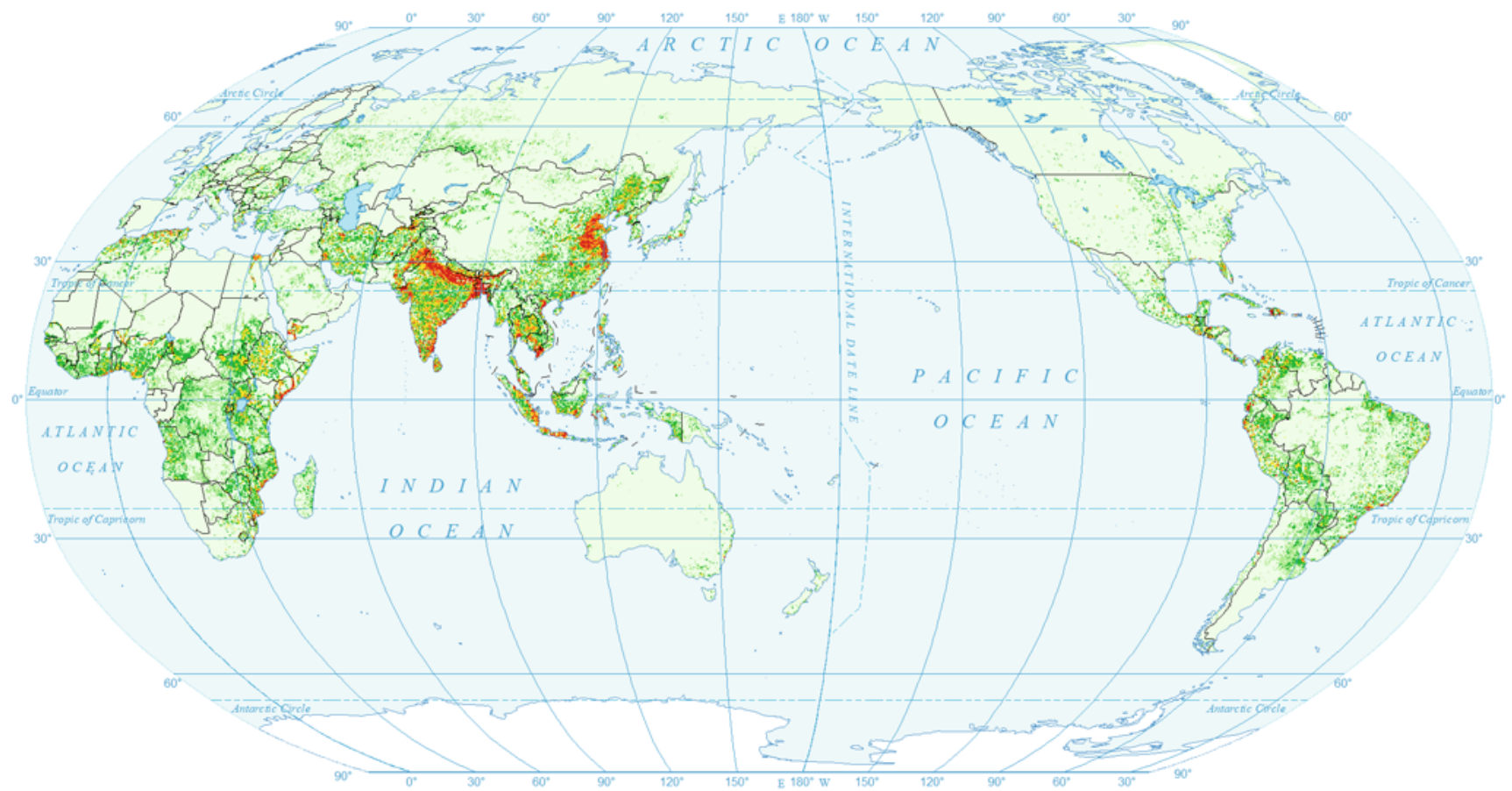

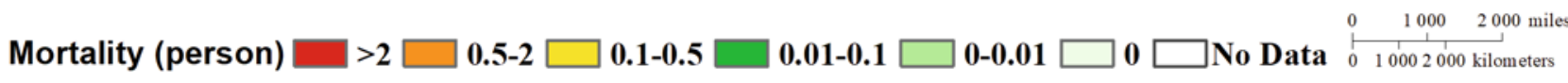




\section{References}

Alfieri, L., L. Feyen, F. Dottori, and A. Bianchi. 2015. Ensemble flood risk assessment in Europe under high end climate scenarios. Global Environmental Change 35: 199-212.

Arnell, N.W., and S.N. Gosling. 2016. The impacts of climate change on river flood risk at the global scale. Climatic Change 134 (3): $387-401$.

CRED (Centre for Research on the Epidemiology of Disasters) and UNISDR (United Nations International Strategy for Disaster Reduction). 2018. Economic Losses, Poverty \& Disaster (19982017). https://www.emdat.be/publications.

CRED (Centre for Research on the Epidemiology of Disasters). 2019. 2018 Review of Disaster Events. Brussels, 24 January 2019. https:// www.emdat.be/publications.

Dottori, F., P. Salamon, A. Bianchi, L. Alfieri, F.A. Hirpa, and L. Feyen. 2016. Development and evaluation of a framework for global flood hazard mapping. Advances in Water Resources 94: 87102.

IPCC (Intergovernmental Panel on Climate Change). 2012. Managing the Risks of Extreme Events and Disasters to Advance Climate Change Adaptation. A Special Report of Working Groups I and II of the Intergovernmental Panel on Climate Change, ed. C.B. Field, V. Barros, T.F. Stocker, D. Qin, D.J. Dokken, K.L. Ebi, M.D. Mastrandrea, K.J. Mach, et al. Cambridge, UK: Cambridge University Press.

Jongman, B., H.C. Winsemius, J.C.J.H. Aerts, E.C. De Perez, M. Van Aalst, W. Kron, and P.J. Ward. 2015. Declining vulnerability to river floods and the global benefits of adaptation. Proceedings of the
National Academy of Sciences of the United States of America 112 (18): 201414439.

Jonkman, S.N., J.K. Vrijling, and A.C.W.M. Vrouwenvelder. 2008. Methods for the estimation of loss of life due to floods: A literature review and a proposal for a new method. Natural Hazards 46: 353 389.

Kinoshita, Y., M. Tanoue, S. Watanabe, and Y. Hirabayashi. 2018. Quantifying the effect of autonomous adaptation to global river flood projections: Application to future flood risk assessments. Environmental Research Letters 13(1): 014006.

Liao, X., W. Xu, J. Zhang, Y. Li, and Y. Tian. 2019. Global exposure to rainstorms and the contribution rates of climate change and population change. Science of the Total Environment 663: 644-653.

Lim, W.H., D. Yamazaki, S. Koirala, Y. Hirabayashi, S. Kanae, S. J. Dadson, J.W. Hall, and F.B. Sun. 2018. Long-term changes in global socioeconomic benefits of flood defenses and residual risk based on CMIP5 climate models. Earth's Future 6 (7): 938-954.

Shi, P.J., and R. Kasperson. 2015. World Altas of Natural Disaster Risk. Springer.

Wing, O.E., P.D. Bates, A.M. Smith, C.C. Sampson, K.A. Johnson, J. Fargione, and P. Morefield. 2018. Estimates of present and future flood risk in the conterminous United States. Environmental Research Letters 13(3): 034023.

Winsemius, H.C., B. Jongman, T.I.E. Veldkamp, S. Hallegatte, M. Bangalore, and P.J. Ward. 2018. Disaster risk, climate change, and poverty: Assessing the global exposure of poor people to floods and droughts. Environment and Development Economics 23 (3): 328348.
Open Access This chapter is licensed under the terms of the Creative Commons Attribution 4.0 International License (http:// creativecommons.org/licenses/by/4.0/), which permits use, sharing, adaptation, distribution and reproduction in any medium or format, as long as you give appropriate credit to the original author(s) and the source, provide a link to the Creative Commons license and indicate if changes were made.
The images or other third party material in this chapter are included in the chapter's Creative Commons license, unless indicated otherwise in a credit line to the material. If material is not included in the chapter's Creative Commons license and your intended use is not permitted by statutory regulation or exceeds the permitted use, you will need to obtain permission directly from the copyright holder. 